\title{
PROVAS MATEMÁTICAS EM WITTGENSTEIN
}

\section{Mathematical proofs in Wittgenstein}

\author{
Camila Jourdan \\ Doutoranda em Filosofia pela Pontifícia Universidade Católica do Rio de Janeiro (PUC-Rio), \\ Rio de Janeiro, RJ - Brasil, e-mail: camilajourdan@ hotmail.com
}

\section{Resumo}

Este artigo apresenta alguns problemas da noção de demonstração matemática na Filosofia do segundo Wittgenstein a partir da sua recusa à distinção entre possibilidade e atualidade no contexto normativo. É argumentado que a razão para essa recusa indica algumas pistas para uma abordagem dissolutiva dos problemas apresentados. Os passos de uma prova matemática não podem ser entendidos como justificados por qualquer determinação adicional independente exatamente por causa da necessidade envolvida na prova. Então, esta impossibilidade não pode significar a rejeição da necessidade em questão. Apesar disso, e adicionalmente, este trabalho ressalta que, se os problemas deixados sem solução pela abordagem proposta por Wittgenstein abrem espaço para a atribuição de uma posição aparentemente irrazoável ao autor, isso não anula os argumentos desenvolvidos por ele contra as posições opostas. Assim, ficamos com dois problemas, pois não podemos refutar Wittgenstein por força da irrazoabilidade a ele atribuída, mas também não podemos anular tal irrazoabilidade pela força de seus próprios argumentos.

Palavras-chave: Wittgenstein. Matemática. Provas. 


\section{Abstract}

The article presents some problems of the notion of mathematical demonstration in the second Wittgenstein's Philosophy. The start point is the refuse to the distinction between possibility and actuality in the normative context. It argues that the reason for this refuse indicates some tracks for a dissolutive approach for the presented problems. The steps of a proof in mathematics cannot be understood as a justification for any independent additional determination. The reason for this is the necessity involved in the proof. Then, this impossibility cannot mean the rejection of the necessity in question. In spite of this and additionally, the work emphasizes that, if the problems left without solution for the Wittgenstein's approaches make room for the attribution of an apparently unreasonable position to the author, this does not cancel the arguments developed by him against the opposed positions. Thus, we have two problems, since we cannot refute Wittgenstein by the force of the unreasonability attributed him and we cannot too cancel such unreasonability for the force of his arguments itself.

Keywords: Wittgenstein. Mathematics. Proofs.

GP - Grammaire philosophique

RFM - Remarks on foundations of mathematics

PR - Philosophical remarks

WCV - Ludwig Wittgenstein and the Vienna Circle

\section{INTRODUÇÃO}

O objetivo deste trabalho é apresentar alguns problemas, aparentemente insolúveis, que surgem inevitavelmente quando aceitamos algumas características da noção de 'demonstração' proposta pelo segundo Wittgenstein. Pretende-se mostrar que o que possibilita que cada passo de uma prova matemática possa parecer contingente, na abordagem de Wittgenstein, é fundamentalmente a recusa do autor a uma distinção forte entre em princípio e factual no âmbito normativo da linguagem. De fato, 
tal distinção demonstra-se incoerente e insustentável a partir da diferenciação entre o âmbito empírico e o âmbito normativo da linguagem, central na Filosofia do segundo Wittgenstein. Argumentaremos no sentido de tornar clara a coerência interna inerente a esta radical posição dentro do desenvolvimento do pensamento de Wittgenstein.

\section{A noção de demonstração matemática em Wittgenstein}

O ponto central para entender a concepção de prova matemática em Wittgenstein parte de uma compreensão anterior da sua distinção entre um âmbito normativo e um âmbito empírico da linguagem. Como, para Wittgenstein, a matemática seria um âmbito completamente normativo, as demonstrações matemáticas não poderiam ser pensadas sob o ponto de vista de uma justificação externa ao que é provado. Isso se explica porque uma característica central do âmbito normativo da linguagem, na filosofia de Wittgenstein, consiste justamente em não poder se referir a algo independentemente existente, isto é, não poder ser descritivo. Tal característica segue-se do aspecto necessário do âmbito normativo, isto é, as normas gramaticais só poderiam dizer respeito a um âmbito arbitrário, relativo à determinação do significado, pois, para que uma proposição pudesse ser descritiva de uma realidade, deveria ser possível determinar sobre o que tal proposição fala independentemente da sua verdade, o que é um requisito da possibilidade de verificação empírica. Mas, se este fosse o caso, a proposição já não seria necessária. A independência entre o objeto da proposição e a própria proposição nos forneceria um critério de avaliação da verdade ou falsidade. Por outro lado, no caso de uma proposição necessária, não podemos contar com tal critério porque, tal como argumenta Wittgenstein, o que quer que fosse usado para tanto, já suporia a verdade da própria proposição em questão.

Se eu pudesse descrever a função das convenções gramaticais dizendo que elas são tornadas necessárias por certas propriedades das cores (digamos), isso tornaria as convenções supérfluas, já que, nesse caso, eu poderia dizer precisamente aquilo que as convenções me impedem de dizer. Inversamente, se as convenções fossem necessárias, isto é, se certas combinações de palavras tivessem de ser excluídas como contra-sensos, então, justamente por essa razão, não posso indicar uma propriedade das cores que torne as convenções necessárias já que, então, seria 
concebível que as cores não tivessem esta propriedade, e eu só poderia exprimir isso violando as convenções. [...] Não chamo uma regra de representação uma convenção se ela pode ser justificada em proposições: proposições descrevem o que é representado e mostram que a representação é adequada. As convenções gramaticais não podem ser justificadas descrevendo-se o que é representado. Qualquer descrição deste tipo já pressupõe as regras gramaticais. Isto é, se qualquer coisa tem que ser considerada carente de sentido na gramática que tenha de ser justificada, isso não pode, ao mesmo tempo, passar como dotado de sentido na gramática das proposições que a justificam (PR, 1975, I, 4).

Sendo assim, na medida em que a matemática seria completamente composta por proposições necessárias, a determinação da verdade de suas proposições não seria independente da determinação da semântica destas e, por isso, se vamos continuar falando em 'verdade' neste contexto será somente em um sentido pelo qual não apenas a demonstração determina a verdade das proposições ou fórmulas, mas determina também, e ao mesmo tempo, o significado destas.

Em matemática não existem, primeiro, proposições que têm sentido por si mesmas e, segundo, um método para determinar a verdade ou falsidade de proposições; existe apenas um método, e o que é chamado uma proposição é apenas um nome abreviado para o método (WCV, 1979, I, p. 33).

Esta abordagem condiciona também a conhecida distinção de Wittgenstein entre prova e experimento: proposições matemáticas não poderiam ser empiricamente justificadas simplesmente porque não poderiam ser justificadas por um padrão externo qualquer: "A proposição aritmética não é a proposição empírica: 'quando faço isso, obtenho aquilo' - na qual o critério para meu fazer isso não é supostamente o que resulta disso" (RFM, 1967, VI, 22). Em uma proposição aritmética, o critério para a realização do procedimento é já o seu resultado e, por isso, provas jamais seriam experimentos, senão por uma analogia inadequada. Descrever um experimento não é ainda um experimento, justamente porque, neste caso, o objeto do experimento e o experimento independem, enquanto que, por outro lado, descrever uma prova matemática detalhadamente é já possuir a prova.

Se poderia dizer nestes termos: quando eu procuro alguma coisa, digamos, o Pólo Norte, ou uma casa em Londres, posso fazer uma descrição completa disso que procuro, antes de tê-lo encontrado (ou ter 
descoberto que essa coisa não existe), e, nesse caso, esta descrição será logicamente aceitável. Enquanto que no caso da busca em matemática, se ela não intervém dentro de um sistema, não posso descrever o que procuro, ou posso apenas parecer o descrever, pois se eu pudesse o descrever em todos os seus detalhes, eu já o teria em minha posse, e antes de o ter descrito completamente, não posso estar certo que isso que procuro é logicamente aceitável, e se deixa descrever completamente; isto é, que essa descrição imperfeita justifica precisamente isso que seria necessário para que se pudesse procurar alguma coisa. Ela é apenas, portanto, uma aparência de descrição disso que é procurado (GP, 1980, V, 22).

Uma proposição matemática consistiria sempre em uma regra, e, portanto, não seria jamais uma hipótese a ser testada por um experimento, mas seria, enquanto proposição matemática, um paradigma pelo qual a experiência é comparada e julgada. Resultado e procedimento são indissociáveis quando a determinação é uma norma, isto é, não podemos ter o procedimento com outro resultado, pois, se temos outro resultado, simplesmente temos que dizer que não executamos o procedimento. O problema central da abordagem realista da matemática consistiria, assim, em tratar as normas pelo modelo de uma determinação empírica, isto é, uma determinação externa, tratando as proposições em questão como proposições contingentes, às quais faria sentido atribuirmos verdade ou falsidade, desde que, no modelo da correspondência a um padrão independentemente existente, deveria ser possível identificarmos aquilo que determina a semântica da proposição sem já pressupormos a sua verdade.

É fato, entretanto, que pelo menos durante o chamado período intermediário de sua Filosofia, Wittgenstein trabalha claramente com a ideia de sistemas matemáticos. Tal noção o permite afirmar que a intervenção de uma proposição matemática em um sistema de proposições formalmente similares, permitiria também determinar um padrão de prova para as proposições, garantindo, com isso, o que ele chama o seu controle. Tal controle possibilita que as proposições, pelo menos as decidíveis, tenham sentido independentemente de sua verdade e que, portanto, saibamos pelo que procurar quando tentamos provar ou refutar a proposição em questão. A noção de sistema matemático o permite dizer isso para as proposições decidíveis, isto é, para aquelas em relação às quais dispomos de um método de decisão. 
Para compreender o sentido de 25 X $25=625$, posso perguntar: como se demonstra esta proposição? Mas eu não posso perguntar: como se demonstra ou se demonstraria o seu contrário? Pois, falar da demonstração do contrário de 25 X 25 = 625 não tem sentido. Então, se quero erguer uma questão independente da verdade da proposição, devo falar do controle de sua verdade e não da sua demonstração ou refutação. $\mathrm{O}$ método desse controle corresponde ao que se pode chamar sentido da proposição matemática. A descrição desse método tem um valor geral e diz respeito a um sistema de proposições, digamos às proposições da forma ' $\mathrm{a} \mathrm{X}$ b = c'. O método de controle da verdade corresponde ao sentido da proposição matemática (GP, 1980, II, 23).

De maneira nenhuma, entretanto, isso poderia significar que a proposição fosse verdadeira em princípio. A ideia de uma determinação 'em princípio' para a matemática é rejeitada inúmeras vezes por Wittgenstein, já no período intermediário. Mesmo a noção de 'sistema' não autoriza a distinção entre em princípio e factual na matemática, pois o sentido que ele fornece às proposições não poderia ser entendido jamais como 'a possibilidade em princípio' da verdade destas.

Temos a intuição correta que 'em matemática não pode haver nem realidade nem possibilidade'. Tudo se passa sobre o mesmo plano. E mesmo, em certo sentido, tudo é real. - E isso é exato. Pois a matemática é um cálculo, e o cálculo não diz de um signo que ele é somente possível, ele apenas considera os signos com os quais opera realmente (GP, 1980, II, 40).

A ideia de 'sistema matemático' não autoriza a analogia entre uma proposição matemática e uma proposição empírica, por isso o próprio sentido matemático é já aqui a técnica de cálculo, e é indissociável da determinação da verdade das proposições particulares para as quais serve como controle. A descoberta de um novo método de prova, por exemplo, mudaria, para Wittgenstein, a gramática da proposição matemática, pois que uma sentença se tornasse decidível constituiria não apenas uma mudança em seu valor de verdade, mas, ao mesmo tempo, em seu estatuto. Podemos dizer que, em relação às normas, a semântica e a determinação da verdade não são jamais independentes, pois o oposto de uma proposição matemática (normativa) não é jamais possível. O problema é que, dado que as proposições matemáticas são necessárias, se o sentido das proposições para as quais possuímos um método de 
prova é já determinado antes de efetivarmos a prova, isso parece significar que também seu o valor de verdade o é, mas apenas em princípio, ainda que factualmente não o saibamos. E essa é, de fato, precisamente a conclusão que Wittgenstein deseja recusar. Para ele, essa conclusão é tão nociva do ponto de vista da prosa filosófica sobre que o cálculo, que será preferido dizer, como encontramos nas $R F M$, que a proposição não provada não é sequer ainda uma proposição matemática. "Eu gostaria de dizer: a prova muda a gramática de nossa linguagem, muda nossos conceitos. Ela faz novas conexões e cria os conceitos dessas conexões. (Ela não mantém que eles existem, eles não existem sem que ela os faça)" (RFM, 1967, II, 41). Uma prova matemática não procederia jamais de acordo com um significado já dado em princípio, justamente porque não podemos entendê-la como sendo justificada tendo por base conceitos independentes desta. Como o significado da proposição matemática não é independente da sua prova, este não pode ser entendido jamais como a justificando. É justamente porque o oposto da proposição normativa é impossível, que ela não é justificável, e precisamos desse sistema geral de proposições formais, ele mesmo não independente dos casos particulares que regula ${ }^{1}$, para o controle da proposição matemática: sua verdade não é determinada jamais por uma falsidade também possível.

\section{A recusa à distinção entre atual e em princípio no âmbito normativo}

Considerando o que até aqui expomos, podemos formular o cerne do problema que se coloca para a abordagem de Wittgenstein da seguinte maneira: se é realmente correto que não podemos descrever uma demonstração sem já encontrá-la, e que uma proposição provada não tem o mesmo sentido antes da sua prova que tem após a prova, deveria ser igualmente verdade que não sabemos exatamente o que provamos antes de encontrar a prova e que, portanto, não há mesmo nenhuma necessidade na maneira como uma prova procede. Como se sabe, Michael Dummett

\footnotetext{
Este seria outro passo, independente, da nossa argumentação geral, que não temos a pretensão de desenvolver satisfatoriamente no presente trabalho, cumpre apenas ressaltar que ele é tratado particularmente nas considerações de Wittgenstein sobre a generalidade matemática, na Gramática Filosófica (GP, 1980, II, II), e nas suas análises sobre a indução matemática, também na Gramática Filosófica (GP, 1980, II, VI).
} 
(1959) leu as observações de Wittgenstein sobre a matemática desta forma, isto é, como um convencionalismo radical, de acordo com o qual não haveria qualquer determinação para a necessidade matemática além de nossa livre escolha em aceitar cada passo de uma demonstração como se estabelecendo por livre convenção. De acordo com Dummett, para Wittgenstein, haveria um gap entre nosso assentimento às regras de inferência e nosso reconhecimento de cada aplicação destas como uma aplicação correta, afinal, argumenta Dummett, Wittgenstein mantém que não haveria nada em nossas formulações das regras, nem em nossa mente, nem em qualquer realidade abstrata, que nos compelisse a aceitar as transições feitas a cada passo de uma prova, determinando as aplicações que fazemos de nossas regras. Para Dummett, ao contrário, precisaríamos garantir que, 'uma vez que estabelecemos determinadas construções', não estamos mais livres para decidir a necessidade do que destas se segue, o que não seria, ainda segundo ele, garantido pela abordagem de Wittgenstein. Nunca uma interpretação aparentemente absurda foi tão literal, pois, de fato, é Wittgenstein mesmo quem o diz, mais de uma vez: procedemos em uma demonstração livremente, tomamos decisões: "Estou tentando dizer algo como: mesmo se a proposição matemática parece apontar para a realidade fora dela, ela é ainda apenas a expressão da aceitação de uma nova medida da realidade. [...] Por que não devo dizer: na prova, tomamos uma decisão?" (RFM, 1967, II, 27). De fato, muitas são as razões para não se dizer isso. Crispin Wright (1980), por exemplo, considera este problema a partir da já mencionada suposta modificação conceitual operada pela prova. Parece que apenas seríamos livres para recusar ou aceitar uma prova (ou cada passo seu) exatamente porque ela não se estabeleceria em virtude de um significado previamente dado ou aceito, mas determinaria, ela mesma, o conceito em questão. O problema diz respeito, portanto, justamente à concepção de acordo com a qual as provas matemáticas determinariam ou modificariam o significado dos conceitos envolvidos na proposição provada. A ideia intuitiva envolvida nesta concepção é, como vimos, justamente uma contraposição à tese realista segundo a qual a prova procederia de acordo com um significado já dado, e que a corretude da prova, portanto, seria justificada tendo por base conceitos independentes desta. $\mathrm{O}$ argumento consiste em notar que, como o significado em questão não é independente da prova, este não pode ser entendido jamais como a justificando, e, assim, seria mais adequado, para não tratar a prova como independente, novamente por analogia a um experimento de verificação, 
dizer que a própria prova cria o conceito em questão. Mas, embora a crítica que interdita a consideração da prova como um experimento de justificação seja pertinente, o problema de considerar a prova como constituindo os conceitos envolvidos nela aparece imediatamente, afinal, uma prova parece ser válida justamente em virtude da sua fidelidade ao conteúdo da proposição provada. Então, se é assim, como ela poderia ser necessária e, ainda assim, introduzir ou modificar este conteúdo? Parece óbvio que não somos livres para recusar ou aceitar uma prova, pois cada passo seu se impõe com necessidade, ao que parece, em virtude mesmo das noções ali envolvidas. Além disso, se a proposição apenas recebesse seu sentido ao ser provada, como entenderíamos e tentaríamos provar/refutar conjecturas ainda não provadas/refutadas?

A distinção forte entre normativo e empírico, proposta na Filosofia de Wittgenstein, não implica apenas uma crítica ao realismo matemático, mas, se levada até o fim, implica também uma recusa a toda noção de "possibilidade em princípio', dentro do âmbito normativo, e, portanto, dentro da matemática. Tal interdição é, de fato, a mesma que impossibilita a própria noção de metamatemática: não há uma noção de 'em princípio' adicional no âmbito da matemática porque não há a possibilidade de garantia adicional, seja de que natureza for, para a prática matemática.

O que é uma prova da provabilidade? É diferente da prova da proposição? E uma prova da provabilidade talvez seja a prova de que uma proposiçao tem sentido? Mas, então, tal prova teria de se basear em princípios inteiramente diferentes daqueles nos quais a prova da proposição se baseia. Não pode haver uma hierquia de provas. Por outro lado, não pode haver, em nenhum sentido fundamental, algo como uma metamatemática. Tudo tem de ser de um tipo (ou, o que dá no mesmo, de nenhum tipo) (PR, 1975, XIII, 153).

A ideia de 'em princípio' seria já, e apenas, a própria ideia de uma determinação normativa, para Wittgenstein, isto é, de uma determinação que ultrapassa o factual no sentido que ultrapassa o meramente empírico. É por isso que não faz sentido, para ele, dentro da própria matemática, já completamente normativa, introduzir novamente uma distinção entre 'factual' e 'em princípio'.

Esta talvez seja a diferença central entre a abordagem de Wittgenstein e a do intuicionismo matemático contemporâneo. Como expomos, as análises de Wittgenstein do contexto normativo da matemática 
têm como conclusão que, neste contexto, não há nem pode haver um critério externo em virtude do qual pudéssemos dizer que a sentença é verdadeira para além da sua demonstração, que seria ao mesmo tempo constitutiva do sentido da sentença. Daí a recusa ao realismo. Mas Wittgenstein percebe que isso também significa dizer que, em relação ao âmbito da matemática, as possibilidades supostamente em princípio de uma sentença encontram-se colapsadas ao factual, ou melhor, não há uma possibilidade anterior para a prática normativa. No âmbito necessário da linguagem, a proposição e sua possibilidade se encontram em um único e mesmo nível. Wittgenstein afirma também já nas Philosophical Remarks:

A negação de 'é necessário que p seja válido para todos os membros' é, naturalmente, 'não é necessário que...', em vez de 'é necessário que não...'. Mas agora pensamos: 'se não é necessário que p seja válido para todos os números, certamente ainda é possível que seja.' Mas é aí que está a falácia, já que não percebemos que caímos na maneira extensional de ver as coisas: a proposição 'é possível - embora não necessário - que p seja válido para todos os números’ é um contrasenso (PR, 1975, XIII, 154).

Sendo assim, o cerne da abordagem de Wittgenstein pode ser entendido como uma recusa à separação forte, no âmbito necessário da linguagem, entre o que é 'atual' e o que é 'em princípio', separação que seria, para ele, de fato, uma característica das teorias filosóficas. Para Wittgenstein, a relação entre o âmbito atual e o âmbito em princípio seria interna no âmbito normativo da linguagem, o que significaria dizer que todo 'em princípio' da nossa prática matemática diria respeito já ao atual, na medida mesma em que todo possível seria já necessário.

Quando se separa, em uma determinada linguagem matemática, determinações em princípio de determinações factuais, isso parece permitir falarmos em falsidade mesma em relação ao âmbito normativo, o que aparece pela própria noção de 'justificação' então aplicada ao funcionamento do cálculo, afinal, o que é justificado precisa ser justificado por algo independente do justificado, o que torna contingente a relação em questão. Assim, se estaria tratando as relações em questão ao mesmo tempo como necessárias e como contingentes: necessárias porque determinadas pelo próprio significado; contingentes porque essa determinação seria entendida pelo modelo de uma justificação, que, enquanto tal, seria necessariamente externa. Isso acarretaria que o contrário 
seria possível, afinal, poderíamos apelar a um significado dado independentemente, para a determinação apenas posterior da verdade.

No geral, a noção de em princípio cumpriria a função de expressar a determinação do significado, mas se, no âmbito normativo, este é separado em um âmbito privilegiado, a determinação da semântica parece ser apartada novamente de nossas práticas particulares, e é, com isso, que o mesmo problema conceitual envolvido no realismo retornaria. Tal problema conceitual confunde o normativo com o empírico, o que é, portanto, necessariamente repetido através da distinção entre factual e em princípio no âmbito matemático. Isso se explicaria porque o que a distinção entre em princípio e de fato faz, grosso modo, é forçar, dentro do âmbito normativo, a possibilidade do âmbito 'independentemente dado', o que significa, do ponto de vista da Filosofia do segundo Wittgenstein, introduzir ao mesmo tempo a contingência e a possibilidade de avaliação adicional.

\section{O caminho para uma abordagem dissolutiva}

Mas, se é assim, recusar coerentemente o realismo deve significar manter uma abordagem completamente irrazoável da prática matemática? Pois, se a distinção entre factual e em princípio no âmbito normativo conduz ao retorno de algum tipo de realismo, isso não anula em nada os problemas que se colocam para a compreensão das demonstrações matemáticas quando esta distinção é recusada.

O caminho para uma abordagem dissolutiva deste problema consiste, primeiramente, em notar que a ideia de 'determinações em princípio' deve ser recusada no âmbito matemático precisamente se introduz novamente a ideia de uma justificação adicional. Pois, assim, falha em ressaltar a impossibilidade com a qual nos deparamos no âmbito matemático, e que deve ficar clara para podermos evitar as confusões filosóficas do âmbito empírico com o âmbito normativo. Por outro lado, o que a noção de 'em princípio' desejaria expressar deveria ser dado pelo funcionamento da prática normativa, sem que fosse preciso supor uma separação entre a verdade e a semântica das proposições matemáticas.

Para Wittgenstein, o que não é ulteriormente determinado é necessário, portanto, que não seja ulteriormente determinado não anula esta necessidade, ao contrário, a expressa. A impossibilidade de justificação ou garantia adicional não significa jamais contingência, mas significa precisamente o contrário. 
Dizemos: se realmente seguimos a regra da multiplicação, devemos todos encontrar este mesmo resultado. Agora, se este é apenas algo como um modo histérico de colocar as coisas, que encontramos na fala universitária, isso não nos interessa demais. É, como quer que seja, a expressão de uma atitude no que diz respeito à técnica de cálculo, que aparece em qualquer lugar de nossas vidas. A ênfase no deve corresponde à inexorabilidade dessa atitude tanto em relação às técnicas de cálculo, quanto em relação às demais técnicas relacionadas. O deve matemático é apenas outra forma de dizer que a matemática forma conceitos (RFM, 1967, IV, 67).

O ponto central consiste, portanto, em notar que é característico da normatividade ser justamente uma prática, completamente atual (não há nada oculto), com status 'em princípio', ou, por assim dizer, um colapso entre atualidade e possibilidade. Do ponto de vista da Filosofia de Wittgenstein, podemos realmente dizer que somente quando uma proposição é provada, ela se torna matemática, e isso significa: ela se torna normativa e atemporal. Mas, por que isso parece tão irrazoável? Por que gera tantos problemas? Porque justamente significa uma modificação no sentido da proposição em questão. Mas o que queremos dizer quando mantemos, por outro lado, que uma proposição necessária 'já deve ser sempre verdadeira'? Ora, se seu sentido não muda, tampouco deve mudar sua verdade, afinal, ela é necessária, e não poderia tornar-se necessária, sem mudar de sentido, se não fosse também já determinadamente verdadeira. Isso significa, para Wittgenstein, que o que queremos de fato dizer aqui é 'a proposição necessária, por ser necessária, não tem tempo'. Mas, então, o que significaria dizer, 'agora ela foi, de fato, provada'. Isso deveria significar: 'só agora, ela não tem tempo'. E, se é assim, trata-se necessariamente de outra proposição, pois não apenas o seu valor de verdade mudou, mas também sua semântica e seu uso:

A conjectura não provada não tem papel normativo, por isso o seu sentido muda, porque muda seu emprego, ela passa a ser usada como padrão, em alguma medida, só agora ela se torna uma proposição matemática, porque só agora se torna necessária (RFM, 1967, II, 41).

Faz parte do funcionamento dos padrões normativos que estes sejam tomados como atemporais, sem que isso precise significar que eles eram antes, desde sempre, determinadamente verdadeiros em princípio. Dessa forma, não precisamos dizer que deveria existir, desde sempre, algo 
para justificar a verdade desta proposição, pois a ideia é que se trata apenas de uma proposição matemática, se é atemporal. Ou seja, a proposição matemática é completamente diferente de uma proposição empírica verificada, em relação à qual as condições de verdade permanecem as mesmas. De fato, no caso da proposição matemática, sua falsidade deveria tornar-se impossível, então, não se trata de dizer simplesmente que não existe relação entre a conjectura e a proposição provada, mas de ressaltar que essa relação é completamente distinta da relação entre uma proposição empírica não verificada, e esta mesma proposição após verificada, pois, no caso da proposição matemática, não é apenas sua verdade ou falsidade que é descoberta, mantendo-se ainda o oposto como uma possibilidade em princípio, mas, e isso não é um detalhe sem maiores consequências, toda possibilidade é já uma necessidade quando a sentença é uma norma.

Sendo assim, a leitura que Dummett faz de Wittgenstein está correta na medida em que, realmente, a distinção forte proposta por Wittgenstein entre normativo e empírico o impede de aceitar qualquer separação entre um âmbito em princípio e um âmbito factual no que diz respeito ao contexto normativo da matemática. Entretanto, fazer isso não deve significar negar a determinação da necessidade ou do próprio significado matemático. "Observar a possibilidade como uma sombra da realidade é um dos erros mais profundamente enraizados da Filosofia. Mas, por outro lado, isto pode não ser um erro quando dizemos que esta sombra é a proposição" (GP, 1980, II, III, 10). O caráter 'em princípio' seria dado já, e apenas, com a maneira como a linguagem funciona. Assim, as conclusões irrazoáveis que Dummett atribui a Wittgenstein podem pelo menos ser enfraquecidas se entendermos que (1) aceitar a distinção entre factual e em princípio na matemática conduz fatalmente a alguma forma de realismo e (2) negar esta distinção não pode significar negar a necessidade do âmbito normativo, mas, ao contrário, significa precisamente ser coerente com esta. Portanto, não se trata de abandonar a necessidade da determinação do âmbito necessário, mas apenas manter que esta não possui, e não pode possuir, garantia adicional.

\section{CONCLUSÃO}

O ponto central envolvido nas análises conceituais de Wittgenstein consiste em evitar, por caminhos diversos, a confusão entre o que seria o 
âmbito empírico (contingente) da linguagem e sua função normativa (necessária). "O que eu faço parece sempre ser: enfatizar uma distinção entre a determinação de um sentido e o emprego de um sentido." (RFM, 1967, III, 37). O risco aqui é sempre o mesmo: tomar estas observações elas mesmas como teorias explicativas e/ou revisionistas de nosso emprego da necessidade. Tomar as observações de Wittgenstein nesse sentido é conduzir-lhe mesmo à autocontradição. É preciso mostrar que o discurso matemático está do lado das regras que nos permitem falar sobre as coisas, mas não se pode fazer isso por tomar o próprio discurso matemático como o objeto de uma teoria filosófica, desde que esta teria também pretensão à necessidade, e, nesse sentido, seria uma meta-matemática, o que Wittgenstein recusa justamente pelo próprio caráter normativo da matemática. Então, se ao invés de uma análise conceitual, o discurso de Wittgenstein fosse uma teoria sobre os fundamentos da matemática, sua tarefa mesma já tomaria a matemática como não normativa, porque pareceria explicar o que justamente ele pretende esvaziar como passível de justificação adicional. Desta feita, a aparente carência de uma resposta para problemas erguidos pelas próprias análises de Wittgenstein, ainda que possa levá-las à acusação de insuficientes, é totalmente proposital. Importa-nos antes de tudo clarificar em que as explicações tradicionais se enganam, mostrando as analogias conceituais mal feitas, sem, com isso, erguer mais uma explicação do âmbito normativo. O que Wittgenstein deseja mostrar não é apenas que as demais explicações incorrem em anacronismos conceituais, mas que determinadas explicações não podem ser dadas, que ele não as fornece simplesmente porque elas não podem ser fornecidas, e que qualquer tentativa neste sentido incorrerá fatalmente em uma confusão do empírico com o normativo da linguagem, porque tomará como objeto independente o que só pode funcionar como regra.

Nesse sentido, a má compreensão de Dummett acerca de Wittgenstein consiste em tomar que recusar as explicações teóricas do fato da determinação de nossas práticas dedutivas com regras acarrete negar o próprio fato que consiste na determinação dessas práticas. Essa implicação não é válida, pois negar a teoria que explica um fato não implica jamais negar o próprio fato, a implicação apenas parece proceder mediante a confusão já anterior entre teoria e fato, isto é, nos termos de Wittgenstein, entre prosa e prática.

O método de Wittgenstein consiste em fazer notar por vários caminhos distintos que há uma relação interna onde quer que haja relações necessárias, e é por isso que não seria correto falar em justificações nesses 
casos, desde que justificações consistem sempre em relações externas. Isso significa que Wittgenstein recusaria a posição de Dummett, e dos construtivistas contemporâneos em geral, segundo a qual regras poderiam ser justificadas por outras regras mais fundamentais. "Aqui nós reencontramos constantemente o erro que consiste em ver, na matemática, conceitos gerais e casos particulares" (GP, 1980, II, 40, p. 595). Em matemática, os conceitos gerais são já internos aos casos particulares. Isso também significa que Wittgenstein tem que criticar, pela mesma razão, a possibilidade pela qual as aplicações das regras possam envolver decisões, no sentido de serem contingentes. Se fosse possível decidir seguir ou não uma demonstração, teríamos que ter uma relação externa entre os vários passos da prova, isto é, novamente, o oposto teria que ser possível, e tal consequência é a mesma envolvida na imagem de uma regra justificando a outra, e é precisamente a razão pela qual Wittgenstein deseja recusá-la.

'Tenho um conceito particular de regra. Se nesse sentido, alguém a segue, então desse número pode-se somente chegar àquele.' Isso é uma decisão espontânea. Mas então por que digo 'eu devo', se é minha decisão? Bem, pode não ser isso o que devo decidir? Ser uma decisão espontânea meramente significa: é assim que ajo; não peça nenhuma razão. [...] Naturalmente, quando eu digo 'eu decido espontaneamente', isso não significa: considero que número seria realmente o melhor aqui e então opino (RFM, 1967, VI, 24).

Negar que regras possam ser justificadas implica também negar que poderíamos escolher ou não segui-las, e é nesse sentido que Wittgenstein se afasta tanto da posição dos construtivistas contemporâneos, quanto da posição a ele atribuída por estes.

\section{REFERÊNCIAS}

DUMMETT, Michael. Wittgenstein's philosophy of mathematics (1959). In: Truth and other enigmas. London: Duckworth, 1978. p. 145-165.

DUMMETT, Michael. Wittgenstein on necessity: some reflections (1990). In: The seas of language. Oxford: Oxford University Press, 1993. p. 446-461. 
WITTGENSTEIN, Ludwig. Remarks on foundations of mathematics. Edited by G.H.von Wright, R. Rhees and G. E. M. Anscombe. Translated by G. E. M. Anscombe. Oxford: Blackwell, 1967.

Philosophical investigations. New York: Macmillan Publishing, 1968.

Philosophical remarks. Edited by Rush Rhees and translated by Raymond Hargreaves and Roger White. Oxford: Blackwell, 1975.

. Ludwig Wittgenstein and the Vienna Circle: conversations recordations by Friedrich Waismann. Oxford: Blackwell, 1979.

Grammaire philosophique. Traduit et présenté par Marie-Anne Lescourret. Paris: Gallimard, 1980.

WRIGHT, Crispin. Wittgenstein on the foundations of mathematics. Duckworth: Londres, 1980.

Recebido: $10 / 12 / 2008$

Received: $12 / 10 / 2008$

Aprovado: 04/03/2009

Approved: 03/04/2009 